\title{
«ЗЕЛЕНЫЕ» ПРЕДПОЧТЕНИЯ НЕФТЕГАЗОВЫХ ИНВЕСТОРОВ
}

\section{Н.А. Иванов ${ }^{1}$}

Проблема изменения климата уверенно приобретает финансовое измерение. Климатические риски для финансовых организаций выходят на первый план при обсуждении обязательств стран в соответствии с Парижским соглашением. В последний год, после объявления Еврокомиссией «Европейского зеленого курса» (European Green Deal) и явственной перспективы введения углеродных пограничных налогов мировые инвестиционные объединения и инициативы заметно усилили свою активность.

Пандемия коронавируса внесла свой вклад в переоценку перспектив традиционной углеводородной энергетики. Например, долгосрочный прогноз развития мировой энергетики компании ВР предложил один из наиболее радикальных взглядов на переход мировой энергетической системы на низкоуглеродный путь развития, но причина этого оказалась связанной именно с обрушением мировых рынков в результате пандемии. В отличие от авторов других долгосрочных прогнозов, ВР заложила в свой прогноз вероятность второй волны распространения коронавируса и связанных с ней локдаунов, что должно было привести к дополнительному спаду потребления энергоносителей на мировых рынках. Окажется ли вторая волна столь же разрушительной для рынков, как первая - пока неясно, но возможным следствием таких прогнозов может стать необратимое изменение отношения инвесторов к ископаемым энергоресурсам. Сигналы к этому звучат всё явственнее.

Все больше стран объявляют национальные цели по достижению климатической нейтральности к 2050 году. Все больше крупнейших инвесторов объявляют об изменении стратегии инвестирования и отказе от вложений в высокорисковые углеводородные активы. Как говорится в заявлении крупнейшей инвестиционной компании Black Rock ${ }^{2}$, климатические риски - это финансовые риски.

Российским компаниям необходимо внимательно отслеживать перемены настроения крупнейших мировых инвесторов. Потому что тенденция декарбонизации мировых финансов уже выглядит необратимой и климатические финансовые риски могут в скором времени оказаться чрезмерными.

\section{Изменение глобального подхода к рискам}

Опасность изменения климата стоит на повестке дня международных организаций уже не первое десятилетие, первые инициативы под эгидой ООН относятся к началу

\footnotetext{
${ }^{1}$ Иванов Николай Александрович - кандидат экономических наук, доцент Кафедры международного нефтегазового бизнеса РГУ нефти и газа (НИУ) имени И.М. Губкина

${ }^{2}$ https://www.blackrock.com/corporate/investor-relations/blackrock-client-letter
} 
2000-х годов. Долгие годы вопросы климатических рисков рассматривались исключительно применительно к ответственности государств за нарушение баланса в природной среде, изменение климата было предметом рассмотрения международных конференций и соглашений - сначала в рамках Киотского протокола, затем - Парижского соглашения. Главными сторонами этих договоренностей были страны, берущие на себя обязательства по декарбонизации экономик. При этом в рамках Киотского протокола не стихали споры между развитыми странами и развивающимися - кто должен вносить главный вклад в борьбу с изменением климата. И что должно быть первичным - экономический рост или забота о сохранении природной среды.

Парижское соглашение положило конец таким спорам; страны пришли к общему пониманию, что каждый должен вносить свой посильный вклад в борьбу с эмиссиями парниковых газов. Каждый участник берет на себя обязательство не ухудшать целевые установки по снижению углеродного следа своей экономики, и никто никому не навязывает желательные темпы декарбонизации. При этом совокупные обязательства стран не позволяли говорить о достижимости целей Парижского соглашения - ограничить рост глобальной температуры в наступившем столетии даже двумя градусами Цельсия, не говоря уже о желательном показателе в полтора градуса.

В последние годы резко активизировались международные группы инвесторов. Инициативы $\mathrm{OOH}$ по вовлечению инвестиционного сообщества в процессы борьбы с изменением климата увенчались успехом - количество участников разнообразных инициатив по «ответственному инвестированию», «устойчивому финансированию» и раскрытию финансовой климатической отчетности растет и ширится. Возможно, количество уже перерастает в качество - идея низкоуглеродных инвестиций уже стала господствующей, и инвестиции, скажем, в проекты по добыче угля или строительства угольных электростанций становятся крайне неодобряемыми обществом и, во всяком случае, слишком дорогими, чтобы быть выгодными.

Идея чистого устойчивого развития нашло верный подход к инвесторам - через деньги. Стало очевидным, что неадекватная информация о климатических рисках может привести к обесцениванию активов и нерациональному вложению капиталов. И если раньше на первом месте стояли риски разбалансировки климатической системы, повышения уровня океана, затопления обитаемых территорий, увеличения числа экстремальных природных явлений и т.п., то постепенно фокус смещался. Это изменение фокуса хорошо видно по эволюции докладов Всемирного экономического форума (ВЭФ).

Всемирный экономический форум регулярно публикует доклад о глобальных рисках. В начале 2020 г. был опубликован 15-й доклад - World Economic Forum's Global Risks Report $^{3}$, в котором особо отмечаются риски изменения климата и проводится

\footnotetext{
${ }^{3}$ https://www.weforum.org/reports/the-global-risks-report-2020
} 
параллель между климатическими рисками и геополитической нестабильностью во многих регионах мира.

Доклад стал частью более общего проекта - Глобальной инициативы по управлению рисками (Global Risks Initiative)4, которая должна предложить участникам объединиться для выработки интегральных решений по решению наиболее острых мировых проблем. В частности, предполагается оказывать давление на компании со стороны инвесторов, регуляторов, потребителей и сотрудников с целью противостоять изменению климата.

\section{Инициатива ООН}

Начиная с 2000 года Организация Объединенных Наций, через Финансовую инициативу Программы по охране окружающей среды (United Nations Environment Programme Finance Initiative, UNEP FI) ${ }^{5}$ и Глобальный договор OOH (UN Global Compact) ${ }^{6}$ продвигает принципы корпоративной социальной ответственности и стремится вовлекать компании финансового сектора в стимулирование решения вопросов экологии, социальной сферы и корпоративного управления при управлении инвестициями ${ }^{7}$.

Рисунок 1. Число участников программы PRI (владельцев активов и управляющих) и стоимость активов (собственных и под управлением), трлн долларов.

\footnotetext{
${ }^{4}$ https://www.weforum.org/global-risks

${ }^{5}$ https://www.unepfi.org/

${ }^{6}$ https://www.unglobalcompact.org

7 Глобальный договор ООН в России представлен Национальной сетью Глобального договора ООН. К Глобальному договору ООН присоединились более 50 крупных российских участников, таких как Внешэкономбанк, Северсталь, Роснефть, Русал, Норникель, РусГидро, АФК «Система», РЖД, Лукойл, Сахалин Энерджи, Полиметалл, Водоканал Санкт-Петербурга, Российский союз промышленников и предпринимателей и другие. Кроме того, в России работают несколько десятков представительств международных корпораций, которые также являются участниками Глобального договора ОOH.
} 


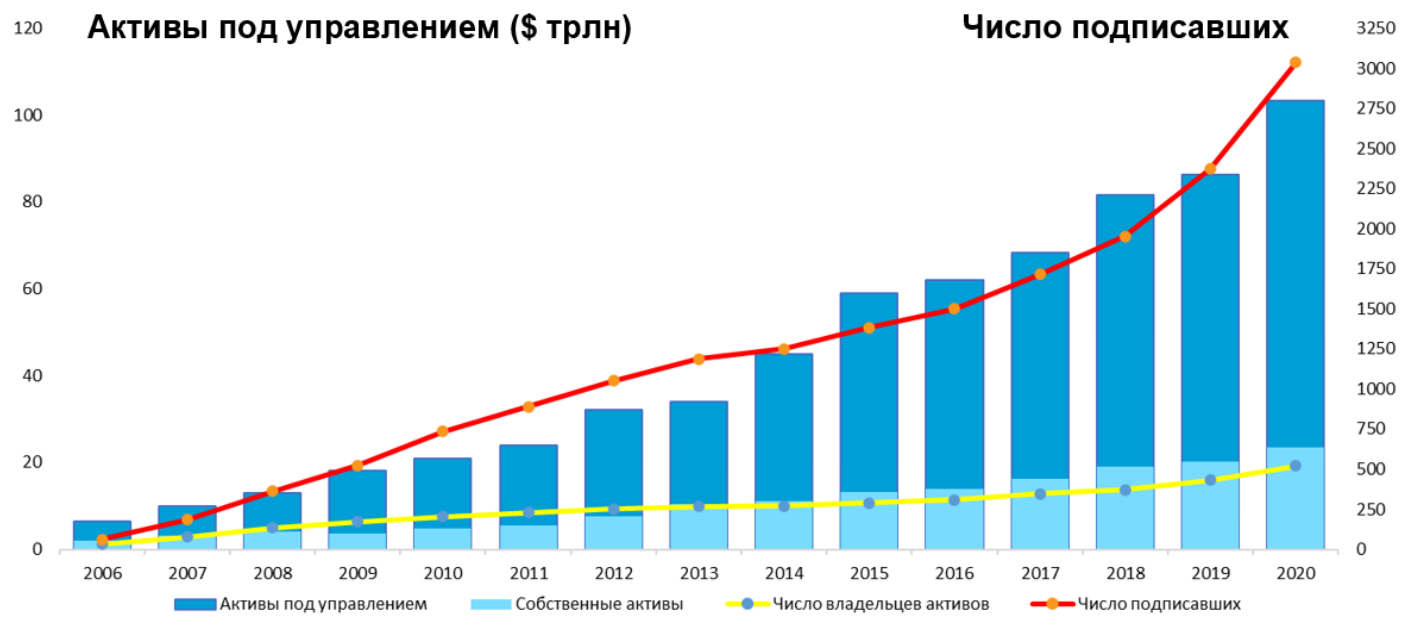

Источник: UN PRI

Эта инициатива в первый же год объединила более 160 организаций, стремящихся решить целый ряд ключевых вопросов экологии, социальной сферы и корпоративного управления по таким направлениям, как банковское дело, управление активами, страхование и частный акционерный капитал, а также в других важнейших областях экономики. В результате Рабочая группа по управлению активами Финансовой инициативы ЮНЕП способствовала достижению глобального консенсуса относительно того, что вопросы экологии, социальной сферы и корпоративного управления имеют непосредственное отношение к бизнесу и являются важными факторами, которые необходимо учитывать в процессе принятия инвестиционных решений и практике владения активами.

В начале 2005 г. генеральный секретарь ООН Кофи Аннан пригласил группу крупнейших мировых институциональных инвесторов присоединиться к процессу выработки Принципов ответственного инвестирования (Principles for Responsible Investment, PRI) ${ }^{9}$. Принципы PRI были объявлены в апреле 2006 г. на Нью-Йоркской фондовой бирже. Всего за год программа PRI получила поддержку свыше 180 участников, разработала рамки для отчетности и оценки, выработала инструменты реализации программы и создала первую глобальную сеть инвесторов, которая готова решать более широкий круг вопросов, связанных с экологическими проблемами, социальной сферой и корпоративным управлением. К 2020 году число участников программы превышает три тысячи.

Таблица 1. Крупнейшие участники программы PRI, владеющие или управляющие активами, превышающими \$250 млрд

\begin{tabular}{|l|l|l|}
\hline Участник & Статус & Страна \\
\hline
\end{tabular}

\footnotetext{
${ }^{8}$ https://dwtyzx6upklss.cloudfront.net/Uploads/g/p/y/globalaumandaoaumexternaluse 110617.xlsx
}

\section{${ }^{9}$ https://www.unpri.org/about-the-pri}




\begin{tabular}{|l|l|l|}
\hline Stichting Pensioenfonds ABP & Владелец активов & Нидерланды \\
\hline State Street Global Advisors (SSGA) & $\begin{array}{l}\text { Инвестиционный } \\
\text { управляющий }\end{array}$ & США \\
\hline Nuveen, a TIAA Company & $\begin{array}{l}\text { Инвестиционный } \\
\text { управляющий }\end{array}$ & США \\
\hline Neuberger Berman Group LLC & $\begin{array}{l}\text { Инвестиционный } \\
\text { управляющий }\end{array}$ & КШанада \\
\hline Manulife Investment Management & $\begin{array}{l}\text { Инвестиционный } \\
\text { управляющий }\end{array}$ & Великобритания \\
\hline Legal \& General Investment & $\begin{array}{l}\text { Инвестиционный } \\
\text { управляющий }\end{array}$ & Франция \\
\hline AXA Investment Managers & $\begin{array}{l}\text { Инвестиционный } \\
\text { управляющий }\end{array}$ \\
\hline APG Asset Management & $\begin{array}{l}\text { Инвестиционный } \\
\text { управляющий }\end{array}$ & Нидерланды \\
\hline Allianz SE & Владелец активов & Германия \\
\hline
\end{tabular}

Источник: UN PRI

\section{Принципы ответственных инвестиций (PRI)}

Принципы ответственных инвестиций OOH (PRI) - это набор из шести принципов, которые обеспечивают глобальный стандарт ответственного инвестирования, который относится к вопросам охраны окружающей среды, социальной сфере и корпоративному управлению (environmental, social and governance, ESG) ${ }^{10}$. Целью следования этим принципам является выполнение обязательств перед бенефициарами, а также более эффективное согласование инвестиционной деятельности с более широкими интересами общества.

Шесть принципов ответственного инвестирования (PRI) основаны на действиях в лучших долгосрочных интересах розничных и институциональных инвесторов, финансовых рынков, экономики, окружающей среды и общества в целом. Организация Объединенных Наций $(\mathrm{OOH})$ поддерживает принципы, и отдельная некоммерческая организация контролирует эту программу.

Организации, подписавшиеся под документом, должны публично заявить о принятии и реализации Принципов ООН для ответственных инвестиций (PRI). Ниже приведены шесть принципов наряду с неисчерпывающим списком способов, которыми организации могут продвигать каждый принцип.

${ }^{10}$ https://esg.org/ 
1. Мы включим вопросы экологического, социального и корпоративного управления (ESG) в процесс инвестиционного анализа и принятия решений. Подписавшие стороны могут следовать первому принципу, поддерживая разработку связанных с ESG инструментов, показателей и анализа и поощряя исследования по вопросам, связанным с ESG.

2. Мы будем активными владельцами и включим вопросы ESG в нашу политику и практику владения. Подписавшие стороны могут следовать второму принципу, поощряя и защищая права акционеров и взаимодействуя с компаниями по вопросам ESG.

3. Мы будем добиваться надлежащего раскрытия информации по вопросам ESG теми компаниями, в которые мы инвестируем. Организации могут попросить компании интегрировать вопросы ESG в свои годовые финансовые отчеты и запросить стандартизованную отчетность по вопросам ESG с помощью таких инструментов, как Глобальная инициатива по отчетности, - отчетность об устойчивом развитии, которая просит организации раскрывать их влияние на вопросы изменения климата, прав человека, коррупции и других проблем устойчивости.

4. Мы будем способствовать принятию и реализации принципов в инвестиционной отрасли. Подписавшие стороны могут сообщать поставщикам услуг о своих ожиданиях относительно ESG и пересматривать отношения с теми, кто не придерживается руководящих принщипов ESG.

5. Мы будем работать вместе, чтобы повысить эффективность внедрения принципов. Организации могут сотрудничать для решения новых проблем и поддержки инициатив путем обмена информацией, инструментами и ресурсами.

6. Мы будем публиковать доклады о нашей деятельности и прогрессе в реализации принципов. Благодаря этому принципу организации стремятся повысить осведомленность о принципах ESG среди более заинтересованных сторон и бенефициаров.

Подписавшие стороны добровольно соглашаются поддерживать и продвигать принципы, улучшая управление рисками и стремясь ответственно увеличить доходность инвестиций. Подписавшие стороны демонстрируют свою приверженность ответственному инвестированию и более устойчивой финансовой системе и присоединяются к сообществу единомышленников. Чтобы иметь право стать подписавшим, организация должна быть владельцем активов, инвестиционным менеджером или поставщиком услуг.

Примерами владельцев активов являются пенсионные фонды, суверенные фонды, страховые и перестраховочные компании и другие финансовые учреждения. Инвестиционные менеджеры - это организации, которые контролируют активы третьей стороны на институциональном или розничном рынке. Поставщики услуг 
предлагают продукты или услуги владельцам активов или управляющим инвестициями.

Подписавшие стороны должны подписать декларацию на фирменном бланке, чтобы взять на себя обязательства по включению вопросов экологического, социального и корпоративного управления (ESG) в свой инвестиционный анализ и решения, продвигать Принципы ответственных инвестиций (PRI) в инвестиционной отрасли и публично сообщать о своем прогрессе в реализации принципов.

\section{Инициатива G20}

Одной из наиболее существенных функций финансовых рынков является ценовая оценка рисков, которую можно использовать при принятии решений об эффективном управлении активами. Своевременное и полное раскрытие информации об операциях и результатах финансовой деятельности представляет собой основу отчетности, но всё более важно понимать, при каком стиле корпоративного управления и с учетом каких рисков получены представленные результаты.

Финансовый кризис 2007-2008 гг. показал, какое влияние слабое корпоративное управление и недостатки в управлении рисками могут оказывать на стоимость активов. В результате возникла потребность в прозрачности корпоративных процедур, стратегии и практики управления рисками. В условиях отсутствия информации инвесторы могут неверно оценивать стоимость активов, что приведет к ошибочному вложению капиталов.

В апреле 2015 г. министры финансов и управляющие центральных банков Группы 20 ведущих экономически развитых стран (G20) поручили Совету по финансовой устойчивости (Financial Stability Board, FSB) провести исследование на тему, как государственные и частные компании финансового сектора отражают в своей отчетности вопросы противодействия изменению климата. Частью этого обзора была информация о поддержке решений об ответственном инвестировании, страховании, кредитовании и оценке рисков, связанных с изменением климата.

Чтобы помочь идентифицировать информацию, необходимую для оценки соответствующих рисков, FSB образовал рабочую группу по финансовой отчетности, связанной с изменением климата - Task Force on Climate-related Financial Disclosures, $\mathrm{TCFD}^{11}$. Рабочей группе было поручено разработать добровольную финансовую отчетность, которая помогала бы инвесторам и другим заинтересованным участникам рынка понимать материальное выражение климатических рисков и давать им количественную оценку.

В июне 2017 г. рабочая группа TCFD выпустила окончательные рекомендации компаниям и другим организациям ${ }^{12}$ по включению вопросов, связанных с

\footnotetext{
${ }^{11}$ https://www.unepfi.org/banking/tcfd/

${ }^{12}$ https://assets.bbhub.io/company/sites/60/2020/10/FINAL-2017-TCFD-Report-11052018.pdf
} 
изменением климата, в их регулярную финансовую отчетность. Рекомендации составлены таким образом, чтобы им можно было следовать организациям из различных секторов, работающим в разных юрисдикциях.

Главным образом, следовать рекомендациям должны организации финансового сектора, включая банки, страховые компании, управляющие активами, владельцы активов. Владельцы и управляющие крупными активами находятся на вершине инвестиционной цепочки и оказывают большое влияние на организации, в которые инвестируют, а потому могут требовать наилучшего раскрытия климатически значимой финансовой информации.

Рабочая группа рекомендует организациям включать климатическую финансовую информацию в свои основные годовые отчеты. В большинстве стран, входящих в G20, публичные компании несут юридическую обязанность раскрывать финансовую информацию, включая важную климатическую финансовую информацию. Рабочая группа TCFD считает, что климатическая тематика касается многих организаций и эти рекомендации должны быть полезными при составлении отчетов даже по действующим требованиям, не содержащим вопросов финансовой оценки климатических рисков.

Рекомендации структурированы по четырем темам, представляющим ключевые элементы деятельности организаций: корпоративное управление, стратегия, управление рисками, а также показатели деятельности и цели развития.

РЕКОМЕНДАЦИИ ПО РАСКРЫТИЮ ИНФОРМАЦИИ

1. Корпоративное управление. Необходимо раскрыть отношение в организации к вопросам рисков и возможностей, связанных с изменением климата.

А) Раскрыть отношение совета директоров к климатическим рискам и возможностям.

Б) Раскрыть роль менеджмента в оценке и управлении климатическими рисками и возможностями.

2. Стратегия. Раскрыть действительное и потенциальное воздействие климатических рисков и возможностей на бизнес, стратегию и финансовое планирование.

А) Раскрыть, какие климатические риски и возможности выявлены в краткосрочном, среднесрочном периоде и в долгосрочной перспективе.

Б) Раскрыть влияние климатических рисков и возможностей на бизнес организации, ее стратегию и финансовое планирование.

В) Раскрыть устойчивость стратегии компании, имея в виду различные климатические сценарии, включая сценарий удержания роста глобальной температуры двумя градусами Цельсия. 
3. Управление рисками. Раскрыть, как организация определяет, оценивает и управляет климатическими рисками.

А) Раскрыть методику определения и оценки климатических рисков.

Б) Раскрыть способы управления климатическими рисками.

В) Раскрыть, как процессы определения, оценки и управления климатическими рисками инкорпорированы в общую систему управления рисками организации.

4. Показатели и цели. Раскрыть, какие используются показатели и устанавливаются цели для управления климатическими рисками и возможностями.

A) Раскрыть показатели, используемые в организации для оценки климатических рисков и возможностей в соответствии со стратегией и процессом управления рисками.

Б) Раскрыть эмиссии парниковых газов Уровней 1, 2 и, если возможно, 3 (Scopes 1, 2, 3) и связанные с ними риски.

В) Раскрыть цели организации по управлению рисками и возможностями и действия в соответствии с этими целями.

В этих рекомендациях, выпущенных в 2017 году, рабочая группа TCFD сделала упор на важности обеспечить прозрачность оценки риска, связанного с изменением климата, чтобы поддержать эффективные решения по вложениям капитала. После этого по запросу Совета по финансовой устойчивости (FSB) рабочая группа выпустила еще два доклада, описывающие практику отчетности компаний в соответствии с рекомендациями TCFD. Доклад, опубликованный в сентябре 2020 г. ${ }^{13}$, описывает трудности, не позволяющие последовательно и строго следовать рекомендациям TCFD. Важно, что определенные трудности проявились наряду с существенным прогрессом по распространению рекомендаций для участников финансовых рынков.

За последние 15 месяцев число организаций, выразивших свою поддержку TCFD, выросло более чем на 85\% и превысило 1500, включая свыше 1340 компаний с совокупной рыночной капитализацией, превышающей \$12,6 трлн, и финансовые институты, управляющие активами в \$150 трлн. Многие из этих компаний начали применять рекомендации TCFD или продолжили совершенствовать свою климатическую отчетность.

Благодаря содействию Всемирного делового совета по устойчивому развитию (World Business Council for Sustainable Development) ${ }^{14}$, Института международных финансов

\footnotetext{
${ }^{13}$ https://www.unepfi.org/publications/banking-publications/charting-a-new-climate/

${ }^{14}$ https://www.wbcsd.org/
} 
(Institute for International Finance) ${ }^{15}$, Финансовой инициативы программы ООН по охране окружающей среды (UNEP FI), компании, следующие рекомендациям TCFD, объединились для обсуждения наиболее эффективной практики финансовой климатической отчетности.

Параллельно с ростом числа организаций, поддерживающих TCFD, выросло число инвесторов, поддерживающих компании, которые следуют рекомендациям TCFD. Например, более 500 инвесторов с активами под управлением, превышающими \$47 трлн (группа Climate Action 100+), инвестируют в компании - крупнейшие эмитенты парниковых газов и настаивают на том, чтобы они следовали рекомендациям TCFD и отражали вопросы климатической политики в своей инвестиционной практике и отчетности.

Свыше 110 регуляторов и правительственных структур по всему миру поддерживают TCFD, включая правительства Бельгии, Канады, Чили, Франции, Японии, Новой Зеландии, Швеции и Великобритании. Кроме того, центральные банки и контролирующие органы разных стран образовали Сеть по «озеленению» финансовой системы (Network for Greening the Financial System, NGFS) ${ }^{16}$ и советуют компаниям, выпускающим публичную отчетность, следовать рекомендациям TCFD.

Отдельные правительства включают эти рекомендации в свои требования к компаниям. Например, министерство охраны окружающей среды Новой Зеландии планирует сделать климатическую финансовую отчетность обязательной для публичных компаний и крупных финансовых институтов и потребовать, чтобы она соответствовала рекомендациям TCFD ${ }^{17}$. Финансовый регулятор Великобритании также выступил с аналогичным предложением ${ }^{18}$.

Европейская комиссия включила рекомендации TCFD в Руководство по представлению климатической информации (Guidelines on Reporting Climate-Related Information), чтобы отчетность компаний соответствовала требованиям Евросоюза ${ }^{19}$. Европейский Союз наряду с уже 120 странами стремится к достижению углеродной нейтральности к 2050 году ${ }^{20}$. Многие из этих юрисдикций могут ввести законодательное требование по включению климатической финансовой информации в обязательную отчетность, чтобы обеспечить прозрачность рынка.

\footnotetext{
${ }^{15}$ https://www.iif.com/

${ }^{16}$ https://www.ngfs.net/en

${ }^{17}$ https://www.mfe.govt.nz/climate-change/climate-change-and-government/mandatory-climate-relatedfinancial-disclosures

${ }^{18}$ https://www.fca.org.uk/publication/consultation/cp20-3.pdf

${ }^{19}$ https://ec.europa.eu/finance/docs/policy/190618-climate-related-information-reporting-guidelines en.pdf

${ }^{20}$ https://cop25.mma.gob.cl/wp-content/uploads/2020/04/Alianza-11122019-INGL\%C3\%89S.pdf
} 
Около 60\% из 100 крупнейших публичных компаний поддерживают TCFD и учитывают его рекомендации в своей отчетности ${ }^{21}$. После публикации доклада TCFD 2019 года более 700 организации заявили о своей поддержке инициативы, и поддержка эта растет год от года. Тем не менее, влияние климатических рисков на финансовую отчетность компаний пока остается на низком уровне.

В раскрытии финансовой климатической информации лидируют энергетические компании, а также строительные компании и производители строительных материалов. В 2019 финансовом году 40\% соответствующей опубликованной отчетности пришлось на энергетические компании и $30 \%$ - на отрасль строительства и производства стройматериалов.

\section{Инициатива Европейского Союза}

В июле 2020 г. Европейская комиссия выпустила Коммюнике об обновлении финансовой стратегии устойчивого развития (Consultation Document on the Renewed Sustainable Finance Strategy) ${ }^{22}$. Документ опубликован в развитие пакета документов по Европейскому зеленому курсу (European Green Deal) 23 , опубликованного в декабре 2019 г. В марте 2020 г. Еврокомиссия выпустила проект Европейского климатического законодательства ${ }^{24}$, чтобы придать законную силу цели Европейского Союза достичь климатической нейтральности к 2050 году. Пандемия коронавируса COVID-19 убедила лидеров Евросоюза в необходимости ускорить переход к устойчивому развитию, чтобы минимизировать риск ущерба от подобных катаклизмов в будущем.

Финансирование Европейского зеленого курса потребует инвестиций в объеме около 260 млрд евро в год до 2030 г. Но так как Евросоюз стремится сократить эмиссии, эта цифра еще увеличится. В январе 2020 г. в поддержку Green Deal опубликован Инвестиционный план устойчивого развития Европы (Sustainable Europe Investment Plan), призванный мобилизовать государственные и частные инвестиции. В целом планируется привлечь 1 трлн евро в течение следующего десятилетия.

В 2019 г. Европейский инвестиционный банк (ЕIB) опубликовал новую климатическую стратегию и политику финансирования энергетических проектов

\footnotetext{
${ }^{21}$ https://www.forbes.com/global2000/\#75b72b36335d

${ }^{22}$ https://ec.europa.eu/info/sites/info/files/business economy euro/banking and finance/documents/2020sustainable-finance-strategy-consultation-document en.pdf

${ }^{23}$ https://eur-lex.europa.eu/legal-content/EN/TXT/?qid=1576150542719\&uri=COM\%3A2019\%3A640\%3AFIN

${ }^{24}$ https://ec.europa.eu/commission/presscorner/detail/en/IP_20_335
} 
(Energy Lending Policy) ${ }^{25}$, в которых установил, что вся финансовая деятельность банка с конца 2020 года будет проводиться в соответствии с целями Парижского соглашения. Это означает, в частности, прекращение финансирования проектов, связанных с ископаемыми видами энергоресурсов, с конца 2021 года.

Новая Стратегия устойчивого финансирования развивает исходный документ Еврокомисии от 2018 года - План действий по финансированию устойчивого развития (Action Plan on Financing Sustainable Growth). Поскольку Евросоюз поставил цель добиться углеродной нейтральности и бороться с деградацией природной среды, финансовый и промышленный сектора должны подвергнуться значительной трансформации, что потребует значительный инвестиций.

Новая стратегия будет сосредоточена на трех основных темах:

1. Создание прочных оснований для устойчивого инвестирования путем разработки стимулирующей среды, включающей соответствующие инструменты и структуры. Многие финансовые и не только финансовые компании до сих пор предпочитают краткосрочное финансирование вместо того, чтобы разрабатывать долгосрочную стратегию инвестирования, учитывающую риски и возможности устойчивого развития.

2. Создание возможности устойчивого развития для граждан, финансовых институтов и корпораций. Максимальный эффект от создаваемых инструментов на «зеленое финансирование».

3. Климатические риски и угрозы для окружающей среды должны быть под контролем благодаря интеграции системы управления рисками в финансовые институты и финансовую систему в целом. При этом социальные риски должны приниматься в расчет всегда, когда это только возможно.

\section{Инициативы инвесторов}

\section{Группа Climate Action 100+}

В декабре 2017 г. группа, получившая название Climate Action 100+, объявила о пятилетней инициативе, призванной убедить крупнейшие мировые корпорации эмитенты парниковых газов предпринять усилия по выполнению целей Парижского соглашения. К 2020 году к инициативе присоединились свыше 360 мировых инвестиционных компаний, под управлением которых находятся активы, превышающие \$35 трлн. В фокусе внимания инвесторов и некоммерческих участников инициативы находится 161 компания. Опубликован отчет о первой фазе деятельности инициативы, в котором дана оценка соответствия деятельности

\footnotetext{
${ }^{25}$ https://www.eib.org/en/press/all/2019-313-eu-bank-launches-ambitious-new-climate-strategy-and-energylending-policy
} 
группы заявленным целям. Главная цель инициативы - помочь компаниям оценить финансовые риски, связанные с изменением климата, для их активов и обязательств.

Страховая компания AXА предупреждает, что риски повышения глобальной температуры на $2^{\circ} \mathrm{C}$ еще можно покрыть страховыми инструментами, а последствия роста на $4^{\circ} \mathrm{C}$ застраховать уже невозможно. Поэтому ключевая стратегия для инвесторов, которые хотели бы иметь возможность управлять финансовыми рисками для своих портфелей, заключается в финансировании проектов по противодействию изменения климата.

Инициатива Climate Action 100+ главное внимание обращает на компании, бизнес которых ключевым образом влияет на переход к низкоуглеродной экономике главным образом, на крупнейших эмитентов парниковых газов. 161 компания была выбрана по этому критерию - эти компании отвечают за $80 \%$ эмиссий парниковых газов от корпоративного сектора (по данным за 2018 г.). Инвестиции в эти компании должны продемонстрировать стремление к декарбонизации портфельных инвестиций и всей мировой экономики.

Компании были выбраны по двум критериям:

1. 100 компаний с крупнейшими прямыми и косвенными эмиссиями уровней 1,2 и 3 (Scope 1, 2 and 3) по данным MSCI ACWI26, с использованием модели CDP27.

2. '+' - компании, выбранные инвесторами на основе представления, что они могут иметь специфические возможности по продвижению перехода к чистой энергетике, и это важно для снижения климатических финансовых рисков. Таких компаний выбрано 61.

Инициатива Climate Action 100+ требует от инвесторов подписаться под заявлением, что они будут налагать обязательства, соответствующие выполнению целей Парижского соглашения, на компании из этого списка. К настоящему времени заявление подписано более чем 500 инвесторами, в общей сложности управляющими более чем 47 триллионами долларов.

\section{Институциональные инвесторы - IIGCH}

Группа институциональных инвесторов, объединенных идеей борьбы с изменением климата (Institutional Investors Group on Climate Change, IIGCH) ${ }^{28}$ - европейская коллаборация, состоящая из более чем 250 членов из 16 стран, под управлением которых находятся активы стоимостью свыше 33 трлн евро. Миссия группы состоит в мобилизации капиталов для ускорения перехода к низкоуглеродной экономике и

\footnotetext{
${ }^{26} \mathrm{https://www.msci.com/acwi}$

${ }^{27}$ https://www.cdp.net/en

${ }^{28}$ https://www.iigcc.org/
} 
организации взаимодействия между бизнесом, политиками и инвестиционным сообществом.

IIGCC стремится поддерживать и помогает идентифицировать государственную политику, инвестиционную практику и корпоративное поведение, направленные на управление долгосрочными рисками и возможностями, связанными с изменением климата. Программа IIGCC помогает сформировать политику устойчивого финансирования и климатического регулирования для ключевых секторов экономики.

Выработка верных политических рамок позволяет раскрыть благоприятные возможности для инвестирования и привлечь дополнительное финансирование в низкоуглеродные технологии, необходимые для борьбы с угрозой изменения климата. С другой стороны, политическая нерешительность и регуляторная неопределенность создают дополнительные препятствия для инвесторов и ограничивают возможности для вложения капитала.

Работа группы в первую очередь сосредоточена на EC и на глобальном уровне и направлена на взаимодействие с политиками, парламентариями, министрами и другими заинтересованными сторонами с целью убедить их, что существует прямая связь между портфелями инвесторов и переходом к низкоуглеродной экономике. Это дает возможность IIGCC в тесном взаимодействии с членами группы оказать информационную поддержку решений в направлении строительства низкоуглеродного устойчивого мира.

\section{Коалиция глобальных инвесторов}

Коалиция глобальных инвесторов по проблеме изменения климата (Global Investor Coalition on Climate Change) ${ }^{29}$ - объединение четырех партнерских организаций, стремящихся повысить информированность инвесторов о проблеме изменения климата и содействовать выработке климатической политики, направленной на управление рисками. Коалиция организована в 2012 г. в форме платформы для диалога между инвесторами и правительствами с целью распространения низкоуглеродных инвестиционных практик, корпоративных действий и процедур по выявлению климатических рисков и возможностей, а также выработки международной политики по поддержке достижения целей Парижского соглашения.

Коалиция включает Группу азиатских инвесторов (Asia Investor Group on Climate Change, AIGCC) ${ }^{30}$, американскую некоммерческую организацию Церера (Ceres) ${ }^{31}$, Коллаборацию инвесторов Австралии и Новой Зеландии (Investor Group on Climate

\footnotetext{
${ }^{29}$ https://globalinvestorcoalition.org/

${ }^{30}$ https://www.aigcc.net/

${ }^{31}$ https://www.ceres.org/
} 
Change, IGCC) ${ }^{32}$ и Группу институциональных инвесторов (Institutional Investors Group on Climate Change, IIGCC). Регионы, в которых работают партнеры коалиции включают Азию, Австралию, Европу и Северную Америку.

Региональные партнеры совместно работают над исследовательскими проектами и публичными заявлениями и поддерживают глобальные инициативы инвесторов, направленные на управление рисками изменения климата. В 2017 коалиция объединилась с другими партнерами и инвесторами для создания инициативы Climate Action 100+, призванной убедить крупнейших мировых эмитентов парниковых газов в необходимости предпринимать шаги по противодействию климатическим изменениям.

В следующем году произошло объединение с другими региональными организациями для основания крупнейшей мировой инвестиционной инициативы Investor Agenda ${ }^{33}$.

\section{Инициатива Investor Agenda}

Инициатива Investor Agenda призвана содействовать инвесторам в определении научно обоснованных целей по достижению чистых нулевых эмиссий парниковых газов к 2050 г. или раньше с реальными промежуточными целями.

Для достижения целей Парижского соглашения по ограничению роста глобальной температуры 1,5 градусами Цельсия относительно доиндустриального уровня необходимо существенно нарастить инвестиции в низкоуглеродные технологии и энергоэффективность и сократить инвестиции в сектора, эмитирующие больше всего парниковых газов, включая добычу и использование ископаемого топлива.

В 2018 г. Межправительственная группа экспертов по изменению климата (Intergovernmental Panel on Climate Change, IPCC) объявила, что для этого в мире необходимо инвестировать в чистые энергетические технологии в среднем по $\$ 2,4$ трлн в год до 2035 г., и использование угля должно быть практически полностью прекращено к 2050 г.

Investor Agenda поощряет инвестиции в низкоуглеродные энергетические технологии и рекомендует инвесторам отказываться от финансирования проектов, связанным с энергетическим углем - главным источником эмиссий парниковых газов, включая добычу угля и угольную электрогенерацию. Инвесторы должны также интегрировать вопросы изменения климата в свои долгосрочные инвестиционные решения и анализ портфеля активов.

\footnotetext{
32 https://igcc.org.au/

${ }^{33}$ https://theinvestoragenda.org/
} 
Публичная политика должна посылать сигналы и стимулировать перераспределение потоков капитала в мировой экономике. Политики должны создавать условия для инвестиций в низкоуглеродные активы, в механизмы адаптации к изменению климата, обеспечивать условия для справедливого перехода к низкоуглеродной модели для рабочих и сообществ, которых затронет такая перестройка. Политики также должны убедить инвесторов при принятии решений полностью учитывать риски и возможности изменения климата.

Инвесторы, в свою очередь, влияют на политические решения. Так, на Конференции сторон по проблеме изменения климата в декабре 2019 г. в Мадриде (COP25) группа из 631 инвестора, управляющих активами в объеме \$37 трлн, подписала обращение к правительствам ${ }^{34}$, призывающее добиваться выполнения целей Парижского соглашения, содействовать привлечению частных инвестиций в энергетические проекты с нетто-нулевыми эмиссиями и требовать улучшения финансовой климатической отчетности. 